\title{
Patterns and Outcome of Neonatal Intestinal Obstruction in Kanti Children's Hospital
}

\section{Bijay Thapa and Anupama Basnet}

\author{
Department of Paediatric Surgery, Kanti Children's Hospital, Maharajgunj, Kathmandu, Nepal
}

\author{
Correspondence: \\ Bijaya Thapa \\ Department of Paediatric Surgery, \\ Kanti Children's Hospital, \\ Maharajgunj, \\ Kathmandu, Nepal \\ Email: bijaytapa@hotmail.com
}

DOI: $10.3126 /$ jnps.v40i2.29254

Submitted on: 2020-06-03

Accepted on: 2020-06-21

Acknowledgements: None

Funding: Nil

Conflict of Interest: None declared

Permission from IRB: Yes

To cite this article: Thapa $\mathrm{B}$, Basnet $\mathrm{A}$. Patterns and outcome of neonatal intestinal obstruction in Kanti children's hospital. J Nepal Paediatr Soc. 2020;40(2):120-4

\section{ABSTRACT}

Introduction: Neonatal intestinal obstruction is the most common neonatal surgical emergency. More than $75 \%$ of neonatal surgeries are done for the correction of this problem. The outcome of this obstruction mainly depends upon the causes of obstruction, clinical condition of the patient, associated anomalies, expertise and centre where the patient is dealt. This study was undertaken to study the clinical features and outcome of neonatal intestinal obstruction presented in our centre.

Methods: The medical records of all neonates admitted in the surgical NICU were selected and cases with the diagnosis of neonatal intestinal obstruction and managed surgically during two years period from September 1, 2015 to September 1, 2017 were retrospectively reviewed and analysed in regard to age at presentation, sex, weight, gestation, postoperative diagnosis and their outcome.

Results: Out of 235 admitted neonates, 205 cases were treated surgically for intestinal obstruction. There were a total of 154 $(75.2 \%)$ males and $51(24.8 \%)$ females. Mean age at presentation was 4.5 days and average weight was $2.25 \mathrm{~kg}$. Among them, anorectal malformation (ARM) $88(42.92 \%)$, intestinal atresia $59(28.78 \%)$, Hirschsprung's disease $38(18.53 \%)$, malrotation of gut $10(4.87 \%)$ and meconium ileus $10(4.87 \%)$ were the etiology. Among intestinal atresia, duodenal atresia $27(45.76 \%)$ was the commonest one followed by ileal atresia $24(40.67 \%)$, six jejunal atresia $(10.16 \%)$ and two colonic atresia (3.38\%). Overall, 160 neonates survived (78.04\%). Among the survival, Hirschsprung's disease was 34 $(89.47 \%)$, ARM $78(88.63 \%)$, seven malrotation of gut (70\%), six meconium ileus (60\%) and intestinal atresia $35(59.32 \%)$.

Conclusion: Neonatal intestinal obstruction is the most common neonatal surgical emergency in Kanti Children's Hospital. Anorectal malformation was the commonest etiology followed by intestinal atresia and Hirschsprung's disease. Overall survival rate was $78 \%$. Cases with Hirschsprung's disease and anorectal malformation had about $90 \%$ survival rate. Intestinal atresia was the major cause of mortality occupying $53.35 \%$ of total mortality of $21.95 \%$. Mortality is mainly due to delayed diagnosis, referral and intervention which lead to higher complications of cases.

Key words: Anorectal malformation; Hirschsprung's disease; Intestinal obstruction; Meconium ileus

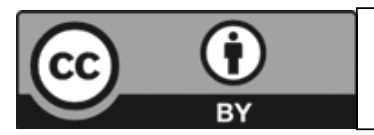

This work is licensed under creative common attribution 3.0 license 


\section{INTRODUCTION}

Neonatal intestinal obstruction constitutes a main bulk of neonatal surgical problems and occurs in approximately one in 2,000 live births. ${ }^{1}$ The causes of obstruction are diverse with different embryological origins, and some etiologies are not yet well defined. Common causes of neonatal intestinal obstruction are intestinal atresia, anorectal malformation (ARM), Hirschsprung's disease (HD), meconium ileus, malrotation etc. ${ }^{2,3}$ It is associated with high mortality if not diagnosed promptly and treated adequately on time. They usually require management by dedicated paediatric surgical and anaesthesia expertise in medical centres equipped with specialised neonatal intensive care. Depending on the etiology and the level of obstruction, prompt surgery may be indicated for treatment. The outcome of these surgical problems postoperatively depend upon multiple factors like gestational age, birth weight, time taken to reach hospital and intervention, associated anomalies and the level of dedicated surgical centres. ${ }^{4,5}$

\section{METHODS}

This was a retrospective study carried out over a period of during two years from September 1, 2015 to September 1, 2017 in the Department of Paediatric Surgery in the tertiary level central hospital, located in Kathmandu, Nepal. All neonates admitted in our SICU with the diagnosis of intestinal obstruction and managed surgically were included in this study. The age, sex, birth weight, clinical features, diagnosis, post- operative diagnosis, management and outcome was noted in proforma and analysed. Descriptive statistics were used for analysis.

\section{RESULTS}

During the study period a total of 235 neonatal cases were admitted in surgical ICU. 205 (87.23\%) cases were diagnosed as intestinal obstruction and underwent surgical intervention. Among them, 154 $(75.12 \%)$ were males and $51(24.87 \%)$ were females. Male to female ratio was 3:1. Out of 205 cases $170(82.92 \%)$ were preterm and $35(17.07 \%)$ were term babies.
Most common cause of obstruction was anorectal malformation - 88 (42.9\%), followed by intestinal atresia 59 (28.78\%), Hirschsprung's disease 38 (18.53\%), malrotation $10(4.87 \%)$ and meconium ileus 10 (4.87\%). Survival rate for Hirschsprung's disease was $89.4 \%, 88.6 \%$ for anorectal malformation, $70 \%$ for malrotation, $60 \%$ for meconium ileus and $59.32 \%$ for intestinal atresia (Table 1).

Most common cause of intestinal atresia was duodenal atresia with $45.76 \%$ followed by ileal atresia $40.67 \%$, jejunal atresia $10.16 \%$ and colonic atresia $3.38 \%$. Survival rate in duodenal atresia was $74.04 \%$, jejunal atresia $66.66 \%$ and ileal atresia $37.5 \%$. Both cases of colonic atresia, which was the rarest among intestinal atresia, survived (Table 2).

Mortality was found to be higher in full-term neonates in comparison to preterm. Mortality rate in preterm was only $14.7 \%$ whereas it was $57.14 \%$ in term babies (Table 3 ).

\section{DISCUSSION}

Neonatal intestinal obstruction is the most common surgical emergency requiring immediate surgical intervention in a new born period. Of the total admission in surgical ICU, 205 (87.23\%) of total cases were operated for intestinal obstruction. Among 205 study population, 154 (75.12\%) were males and $51(24.87 \%)$ were females with a malefemale ratio $3: 1$. Similar observations indicating male predominance were reported by other studies. ${ }^{2,3,6}$ But the study conducted by Shakya VC et al., Burjonrappa $\mathrm{S}$ et al. showed females outnumbered males. ${ }^{7,8}$

The causes of obstruction in our series were ARM (42.92\%), Hirschsprung's disease (18.53\%), intestinal atresia $(28.78 \%)$, meconium ileus $(4.87 \%)$ and malrotation $(4.87 \%)$ (Table 1$)$. Nearly similar observation in the pattern of the etiology was reported by Shah AK et al. with $35.63 \%$ ARM, 23\% Hirschsprung's disease, 14\% intestinal atresia and 57.1\% ARM, 19\% Hirschsprung's disease, $12.7 \%$ intestinal atresia in Ademuyiwa et al. in Nigeria. ${ }^{3,5}$ All these studies showed anorectal malformation as the most common cause of neonatal intestinal obstruction. ${ }^{3,5,9}$ Intestinal atresia 
Table 1. Causes of intestinal obstruction and surgical outcome

\begin{tabular}{|c|c|c|c|c|}
\hline SN & Disease & $\begin{array}{l}\text { Survival } \\
\text { No of } \\
\text { cases }(\%)\end{array}$ & $\begin{array}{l}\text { Mortality } \\
\text { No of } \\
\text { cases (\%) }\end{array}$ & $\begin{array}{l}\text { Total } \\
\text { cases }\end{array}$ \\
\hline 1 & $\begin{array}{l}\text { Anorectal } \\
\text { malformation }\end{array}$ & $\begin{array}{r}78 \\
(88.6 \%)\end{array}$ & $\begin{array}{c}10 \\
(11.36 \%)\end{array}$ & $\begin{array}{r}88 \\
(42.92 \%)\end{array}$ \\
\hline 2 & $\begin{array}{l}\text { Intestinal } \\
\text { atresia }\end{array}$ & $\begin{array}{r}35 \\
(59.32 \%)\end{array}$ & $\begin{array}{c}24 \\
(40.67 \%)\end{array}$ & $\begin{array}{r}59 \\
(28.78 \%)\end{array}$ \\
\hline 3 & $\begin{array}{l}\text { Hirschsprung's } \\
\text { disease }\end{array}$ & $\begin{array}{r}34 \\
(89.47 \%)\end{array}$ & $\begin{array}{r}4 \\
(10.52 \%)\end{array}$ & $\begin{array}{r}38 \\
(18.53 \%)\end{array}$ \\
\hline 4 & Malrotation & $\begin{array}{r}7 \\
(70 \%)\end{array}$ & $\begin{array}{c}3 \\
(30 \%)\end{array}$ & $\begin{array}{r}10 \\
(4.87 \%)\end{array}$ \\
\hline 5 & $\begin{array}{l}\text { Meconium } \\
\text { ileus }\end{array}$ & $\begin{array}{r}6 \\
(60 \%)\end{array}$ & $\begin{array}{c}4 \\
(40 \%)\end{array}$ & $\begin{array}{r}10 \\
(4.87 \%)\end{array}$ \\
\hline & Total & $\begin{array}{r}160 \\
(78.04 \%)\end{array}$ & $\begin{array}{r}45 \\
(21.95 \%)\end{array}$ & $\begin{array}{r}205 \\
(100 \%)\end{array}$ \\
\hline
\end{tabular}

is the second most common cause of intestinal obstruction in our study. Verma A et al. got intestinal atresia as the most common cause. This may be because they did not include ARM cases in their study. ${ }^{2}$

Among the various causes of intestinal atresia in our series, duodenal atresia (45.76\%) was the most common one followed by ileal atresia $(40.67 \%)$, jejunal (10\%) and colonic (3.3\%) (Table 2). Similar to ours Burjonrappa $\mathrm{S}$ et al. had duodenal atresia as the commonest where as Verma A et al. showed the highest incidence of ileal atresia (43.24\%) followed by jejunal atresia (31\%) with duodenal atresia $(20.9 \%)$. Colonic atresia was the least common in both of our studies. ${ }^{2,8}$

The mortality associated with neonatal intestinal obstruction ranges between $20 \%$ and $45 \%$ in developing countries, unlike less than $15 \%$ in Europe. ${ }^{10,11}$ Overall postoperative mortality in our

Table 3. Comparison of mortality in preterm and fullterm newborns

\begin{tabular}{|lrrr|}
\hline Newborn & Survival & Mortality & Total \\
\hline Preterm & 145 & $25(14.7 \%)$ & 170 \\
Full-term & 15 & $20(57.14 \%)$ & 35 \\
Total & 160 & 45 & 205 \\
\hline
\end{tabular}

Table 2. Causes of different intestinal atresia and surgical outcome

\begin{tabular}{|c|c|c|c|c|}
\hline SN & Disease & $\begin{array}{c}\text { Survival } \\
\text { No of cases } \\
(\%)\end{array}$ & $\begin{array}{c}\text { Mortality } \\
\text { No of } \\
\text { cases }(\%)\end{array}$ & $\begin{array}{l}\text { Total } \\
\text { cases }\end{array}$ \\
\hline 1 & & $\begin{array}{r}20 \\
(74.04 \%)\end{array}$ & $\begin{array}{r}7 \\
(25.9 \%)\end{array}$ & $\begin{array}{r}27 \\
(45.76 \%)\end{array}$ \\
\hline 2 & & $\begin{array}{r}4 \\
(66.66 \%)\end{array}$ & $\begin{array}{r}2 \\
(33.33 \%)\end{array}$ & $\begin{array}{r}6 \\
(10.16 \%)\end{array}$ \\
\hline 3 & Ileal atresia & $\begin{array}{r}9 \\
(37.5 \%)\end{array}$ & $\begin{array}{r}15 \\
(62.5 \%)\end{array}$ & $\begin{array}{r}24 \\
(40.67 \%)\end{array}$ \\
\hline 4 & $\begin{array}{l}\text { Colonic } \\
\text { atresia }\end{array}$ & $\begin{array}{r}2 \\
(59.3 \%)\end{array}$ & $\begin{array}{r}0 \\
(0 \%)\end{array}$ & $\begin{array}{r}2 \\
(3.38 \%)\end{array}$ \\
\hline & Total & $\begin{array}{r}35 \\
(59.3 \%)\end{array}$ & $\begin{array}{r}24 \\
(40.67 \%)\end{array}$ & $\begin{array}{r}59 \\
(100 \%)\end{array}$ \\
\hline
\end{tabular}

study was $21.95 \%$ which was higher than reported in international publications. Our mortality is comparable with the studies reported by Seth et al $(20 \%)$ and $22.2 \%$ by Amit et al. $12,13,14$

Survival rate among anorectal malformation was $88.63 \%$, Hirschsprung's disease $89.97 \%$, meconium ileus $60 \%$, intestinal atresia $59.32 \%$ and malrotation $70 \%$. Highest survival was noted in Hirschsprung's disease and ARM and the lowest in intestinal atresia. Shah AK et al. and Talari V et al. in their study also had similar survival rates for anorectal malformation, Hirschsprung's disease and intestinal atresia. But Talari V et al. showed $88 \%$ survival rate for intestinal atresia. This might be because their sample size was low. ${ }^{3,15}$

Out of total mortality $45(21.9 \%)$, intestinal atresia occupies 24 (53.33\%) in our study. Among cases of intestinal atresia, mortality was highest in cases of duodenal atresia as was shown in Deshmukh SN et al. whereas we found ileal atresia with highest mortality and duodenal atresia as lowest mortality. 16 The mortality rates in Nepal and developing countries tend to be very high because these infants are usually underweight and brought late to hospital as compared to western countries. The delay in postoperative oral feeding in atresia unlike other causes of obstruction and long-term need of total parenteral nutrition are the main predicting factors of higher mortality. This delay leads to neonatal sepsis which in a resource limited setting like ours, increases mortality. $7,9,14,17$ 
Most common cause for mortality in our study was septicemia (40.3\%) followed by anastomotic leak (30.1\%) which was similar to the study conducted by Verma $\mathrm{A}$ et al. ${ }^{2}$ This higher rate of mortality in our study could be due to the fact that our hospital is the only referral centre for paediatric surgical patients in the whole country. Patients have to waste time in reaching us which leads to delay in starting the initial treatment. ${ }^{1,4,5,18}$

The high mortality is not directly related to neonatal preterm and low birth weight as seen in the study by Adenmyiwa et al. ${ }^{5}$ They have seen late presentation to the hospital after birth beyond two days of life as the main cause of mortality in their series. In our series mortality is seen more in neonates who were presented to us beyond average age of four days. Thus this high mortality could be prevented if they were diagnosed and managed early. ${ }^{4}$ Neonates delivered in remote areas need to travel several hours to get to a tertiary specialist hospital that offers neonatal surgical services during which time their condition may deteriorate, leading to higher operative risk and mortality. Early recognition and immediate treatment of surgical conditions in the new-born infant is, therefore, very important. ${ }^{4,6,18}$

Therefore, early diagnosis and timely intervention in dedicated neonatal surgical intensive care are undoubtedly the crucial factors in improving outcome in neonatal intestinal obstruction. Paediatricians are usually the first attending physician for early diagnosis in most instances. So, both paediatricians and surgeons have a contributing role in reducing neonatal mortality within existing facilities. Education and training to all birth attendants and village health workers in recognition of signs of obstruction (e.g. bilious vomiting, abdominal distension, failure to pass meconium, imperforate anus), primary management and early referral to paediatric surgical centres may further reduce mortality from neonatal intestinal obstruction in developing world like ours. ${ }^{1,3,10,19-21}$

Our study provides a valid representation of pattern and outcome nationwide. There is a need for more studies in depth on this topic of neonatal intestinal obstruction. We hope in coming years further studies will be done on this topic with further analysis on correlation of different variables like birth weight, socioeconomic condition, etc.

\section{CONCLUSIONS}

Neonatal intestinal obstruction is the commonest neonatal surgical emergency in Kanti Children's Hospital. Anorectal malformation is a leading cause of obstruction followed by intestinal atresia. The incidence is higher in males than female with overall male to female ratio of 3:1. Overall survival rate is $78 \%$ with Hirschsprung's disease and $90 \%$ with anorectal malformation. Intestinal atresia is the major cause of mortality occupying $53.35 \%$ of total mortality. The mortality is more in neonates usually presenting late with severe complications and associated anomalies. Early diagnosis, early intervention, dedicated staff and well equipped neonatal intensive care units are the major factors in improving postoperative outcome.

\section{REFERENCES}

1. Sarma VP, Menon SS. The approach to a neonate with suspected intestinal obstruction: the paediatric surgical perspective. Int Surg J. 2019;6(11):4198-202. http://dx.doi.org/10.18203/2349-2902.isj20195156

2. Verma A, Rattan KN, Yadav R. Neonatal intestinal obstruction: A 15-year experience in a tertiary care hospital. J Clin Diagn Res. 2016;10(2): SC10. DOI: 10.7860/JCDR/2016/17204.7268

3. Saha AK, Ali MB, Biswas SK, Sharif HZ, Azim A. Neonatal intestinal obstruction: patterns, problems and outcome. Bangladesh Med J Khulna. 2012;45(1-2):6-10. https://doi.org/10.3329/bmjk.v45i1-2.13638

4. Narang M, Kaushik JS, Sharma AK, Faridi MM. Predictors of mortality among the neonates transported to referral center in Delhi, India. Indian J Public Health. 2013;57(2): 100. DOI:10.4103/0019-557X.115003

5. Ademuyiwa AO, Sowande OA, Ijaduola TK, Adejuyigbe O. Determinants of mortality in neonatal intestinal obstruction in Ile Ife, Nigeria. Afr J Paediatr Surg. 2009;6(1):11. DOI: 10.4103/0189-6725.48568 
6. Mohammed M, Amezene T, Tamirat M. Intestinal obstruction in early neonatal period: A 3-year review of admitted cases from a tertiary hospital in Ethiopia. Ethiop J Health Sci. 2017;27(4): 393-400. DOI: 10.4314/ejhs. v27i4.10

7. Shakya VC, Agrawal CS, Shrestha P, Poudel P, Khaniya S, Adhikary S. Management of jejunoileal atresia's: an experience at eastern Nepal. BMC Surg. 2010;10:35. DOI: https://doi.org/10.1186/1471-2482-10-35

8. Burjonrappa S, Crete E, Bouchard S. Comparative outcomes in intestinal atresia: a clinical outcome and pathophysiology analysis. Pediatr Surg Int. 2011;27(4):437-42. DOI: https://doi.org/10.1007/s00383-010-2729-8

9. Ameh EA, Chirdan LB. Neonatal intestinal obstruction in Zaria, Nigeria. East Afr Med J. 2000;77(9):510-3. DOI: 10.4314/eamj. v77i9.46702

10. Islam SS, Nowshad MA, Jator A, Faisal I, Ahmed M. Etiology and Treatment Outcome of Neonatal Intestinal Obstruction in a Tertiary Hospital. TAJ J Teach Assoc. 2009;22(2):198-203. DOI: https://doi.org/10.3329/ taj.v22i2.37723

11. Bustos GL, Orbea CG, Domínguez OG, Galindo AI, Cano IN. Congenital anatomic gastrointestinal obstruction: prenatal diagnosis, morbidity and mortality. An Pediatr (Barc). 2006;65(2):134-9. DOI: https://doi.org/ $10.1157 / 13091482$

12. Seth A, Chanchlani R, Rakhonde AK. Neonatal gastrointestinal emergencies in a tertiary care center in Bhopal, India: A prospective study. IJSS Journal of Surgery. 2015;1(5):1-4. DOI: 10.17354/SUR/2015/29

13. Chirdan LB, Uba AF, Pam SD. Intestinal atresia: management problems in a developing country. Pediatr Surg Int. 2004;20(11):834-7. DOI: https://doi.org/10.1007/s00383-004-1152-4

14. Nagpure A, Wardhane S, Gubbi S, Singh S, Gupta A, Gupta P. Etiological Spectrum of Neonates Presenting with Intestinal Obstruction at A Tertiary Care Centre. JMSCR. 2016;4(5):10562-7. DOI: http://dx.doi.org/10.18535/ jmscr/v4i5.29

15. Talari V. A Clinical Study of Neonatal Intestinal Obstruction Abstract: IOSR J Dent Med Sci. 2017;16(8):8-14.

16. Deshmukh SN, Maske AN. Clinical study and management of intestinal obstruction in infants. Int Surg J. 2016;3(2):927-31. DOI: http://dx.doi.org/10.18203/2349-2902.isj20161169

17. Dalla Vecchia LK, Grosfeld JL, West KW, Rescorla FJ, Scherer LR, Engum SA. Intestinal atresia and stenosis: a 25-year experience with 277 cases. Arch Surg. 1998;133(5):490-7. DOI:10.1001/archsurg.133.5.490

18. Haider N, Fisher R. Mortality and morbidity associated with late diagnosis of anorectal malformations in children. Surgeon. 2007;5(6):327-30. DOI: https://doi.org/10.1016/S1479-666X(07)80083-7

19. Osifo OD, Okolo JC. Neonatal intestinal obstruction in Benin, Nigeria. Afr J Paediatr Surg. 2009;6(2):98. DOI: $10.4103 / 0189-6725.54772$

20. Sloan K, Wagener S. Updates In: Hirschsprung's Disease And Anorectal Malformations. J Pediatr Surg Spec. 2016;10(3).

21. Desoky SM, Kylat RI, Udayasankar U, Gilbertson-Dahdal D. Managing neonatal bowel obstruction: clinical perspectives Res Reports Neonatol. 2018;8. DOI: https://doi.org/10.2147/RRN.S125760 